Ana Fuentes-Martínez

https://doi.org.10.26881/ae.2020.17.03

ORCID: 0000-0002-1748-8837

University West, Trollhättan, Sweden

\title{
From a technology acceptance model to a practice acceptance model
}

Computer programming is the process of devising and arranging the necessary instructions that will lead the computer to perform a task (eg. Papert, Harel 1991). It is a powerful skill that has recently been incorporated in the Swedish k-12 mathematics curriculum as a means of solving problems and simulating mathematical processes. Despite programming being used broadly in most mathematics activities outside academia (Rule 2002), the reform has triggered substantial resistance among teachers and trade unions (Larsson 2017) and accommodating the new requirements with traditional core knowledge in mathematics has proven to be challenging even for teachers with previous programming experience (Fuentes Martinez 2021). The purpose of this paper is therefore to examine the factors and preconditions that might influence a successful integration of computer programming in the mathematics curriculum. The analysis departs from the technology acceptance model (TAM) (Chuttur 2009; Davis, Bagozzi, Warshaw 1989) and rises the discussion about whether programming could be considered a technology or a practice, along other pedagogical practices of mathematics teachers. With these ideas in mind, a practice acceptance model is outlined in an effort to capture the connotations and subtleties of similar challenges in post-digital education ${ }^{1}$.

\footnotetext{
${ }^{1}$ Postdigital education is here used to refer to current and future school practices in which the distinction between the digital and the non-digital is not essential in the design and implementation of educational activities (Fawns 2019).
} 


\section{The technology acceptance model}

The TAM is an information systems theory that illustrates how people approach and use a technology. Originally, TAM was developed for explaining and predicting users' acceptance of computer systems in the workplace (Davis 1993; Davis, Bagozzi, Warshaw 1989). Since then, it has proved to be a valuable framework for understanding the reasons why many other technologies become effectively used in a wide range of situations. Outside workplaces, TAM has enabled explanatory models for a large variety of system implementations such as customers responses in retail websites (Lee, Fiore, Kim 2006), patients' relation to technology mediated health care (Kamal, Shafiq, Kakria 2020), or pupils use of educational robots (Shih et al. 2011). Teachers' adoption of technologies has also been subject to several TAM analyses that evaluate a set of technology-related attitudes and beliefs to explain a teacher's intentions to use technology in their professional activities and consequent their actual use of it (eg. Fuentes Martinez 2019; Scherer, Siddiq, Tondeur 2020).

In studies addressing TAM, technology is presented in two very different costumes. It is either a specific digital system (a chat robot, a virtual doctor, a programming language...) or it is blackboxed under the assumption that we all share a common understanding of what the abstract concept of technology entails (Orlikowski, Iacono 2001). According to Kline (2003), technology includes all human-made artifacts with the purpose of enhancing the outcomes of an activity. However, in TAM literature, there is a clear inclination to presuppose that technology refers to - or at least includes - digital components.

Another prevailing trait found in many of the studies that use the TAM is the fact that the technology is expected to enhance some activity that was already taking place before the introduction of the artifact, i.e., technology is seen as a service to fulfill a greater purpose, not an end in itself. Those studies take a stance on the basis of an alien technology being introduced in an otherwise functioning system to improve a certain task or overcome perceived difficulties. In the same line, Kemp, Palmer, and Strelan (2019) talk about compatibility to express the way some educational artifacts align with some teaching preferences better that others. This reflection perpetuates the idea that the teacher's methodology and the curriculum to be taught precede and subdue the technology that is to be deployed. In the context of the relation between computer programming and mathematics in the curriculum, the narrative revolves around terms such as "integrating" or "incorporating", that is, an addition to the existing curricula. However, a different view would be that programming in mathematics is about a new teaching mindset, a new practice built upon computational thinking. 


\section{The slippery concept of acceptance}

Acceptance is generally understood in opposition to resistance or unwillingness. Trying to define acceptance, Adell (2007) found that the way the concept was operationalized in TAM literature could be classified into five categories, ranging from shallow adoption to emotional connection, willingness, and joyful use. Teo and Van Schalk (2009) differentiate acceptance from support and mean that acceptance relies on the willingness to capitulate to some external constraint (e.g., a new curriculum) while support includes appreciation and even pride and satisfaction in doing so. In both cases acceptance is inherent to the individual, her personal attitudes, expectations, and experiences. Acceptance comes therefore from the teacher's own evaluation of the technology and the idiosyncratic benefits of using it (e.g., effective assignment distribution, increased pupil motivation or enabled field trips arrangements). Naturally, those advantages will only influence the level of acceptance if they are known, understood, and trusted by the teacher. Acceptance in our context could be viewed as the degree to which a mathematics teacher intends to include computer programming in her teaching.

\section{TAM variables}

The TAM model is usually depicted as shown in figure 1 . The core of the diagram is actual use, which can be measured using frequency (how often the technology is used), amount of time spent with the technology, and diversity of usage. The factors that lead to actual use are mediated by behavioral intention (BI) which in turn depends on attitude. In other words, the user's overall impression of the technology will form the intention.

Attitude resides in the individual, but it is influenced by external variables such as (a) perceived usefulness (PU), (b) to which degree an individual believes that the technology will be useful to achieve personal goals and, (c) perceived ease of use (PEoU): to which degree an individual believes that using the technology will be free from effort.

Social Influence tries to capture to which the degree the user's social environment expects the technology to be used. People's behaviors are influenced by their peers and how widespread they think a particular technology is. This external variable includes also whether the use of the technology is compulsory. For example, this would be the case for an educational platform channeling all communication with custodians or a new curriculum appointed by the National Agency for Education.

Facilitating Conditions relate to the user's beliefs regarding access to organizational and technical resources that support the use of the technology. In the context 
of this paper, facilitating conditions could include training in computer programming and access to programmable devices. Facilitating conditions will influence the actual use once the behavioral intention is formed.

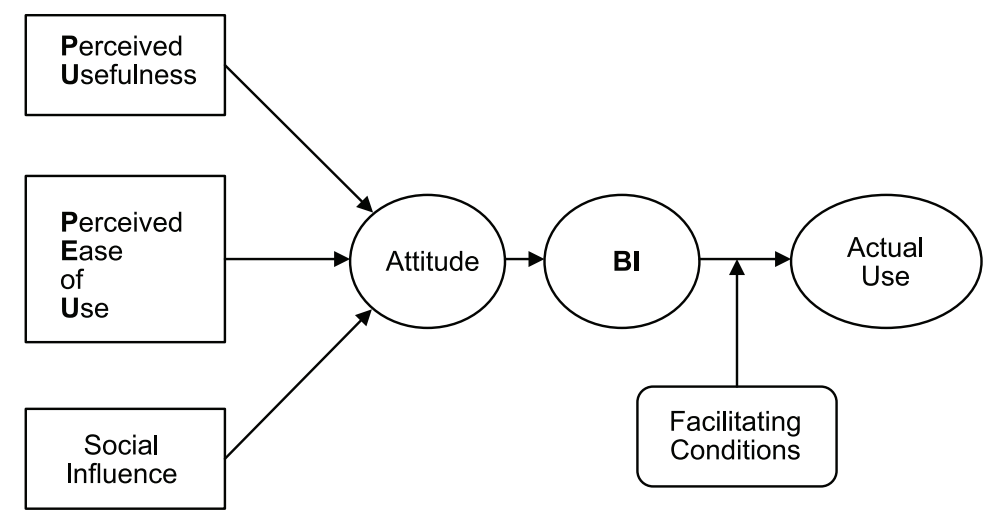

Figure 1: Technology acceptance model adapted from Kemp, Palmer, and Strelan (2019)

\section{A practice acceptance model}

The discussion above leaves an open question regarding whether the introduction of computer programming in the mathematics curriculum could be fruitfully analyzed within the TAM framework. The crucial issue is to which extent programming knowledge could be considered a technology. Is computer programming an artifact to which one could assign certain materiality?

Orlikowski provides several examples of the "material properties" of software, such as menus provided to interact with the program (Orlikowski 2000: 406). Help-desk technicians use queuing software to assign jobs or document previous solutions, which Leonardi means are examples of "material features" (Leonardi 2007: 816). In both cases, materiality deals with properties of the software - the technology that allow users to execute some action. The materiality of software is the result of a previous programming activity, but the programming activity itself seems to escape the scope of materiality. In order to replicate the explanatory benefits of TAM for the introduction of computer programming in the mathematics curriculum, the framework will need to be modified. The technology is no longer the object that needs to be accepted, but only one of the factors allowing a whole new practice to be embraced.

Moving the focal point from technology to practice allows for a different analysis that emphasizes the importance of context, learning and change. Wenger (1998) suggests that individual practitioners are guided by community rules of practice. 
Technology is therefore embedded in a community of practice. A practice acceptance model should therefore zoom out from an individual acceptance to a broader community acceptance. As a consequence, the purpose of the model should be to explain and predict the acceptance of a new practice in a community, not merely as the sum of individual acceptances but as a social recognition of behavior.

\section{Literature}

Adell E., 2007, The concept of acceptance, ICTCT, https://www.ictct.net/wp-content/ uploads/20-Valencia-2007/ictct_document_nr_485_Adell.pdf [access: 20.07.2021].

Carr W.,1987, What is an educational practice?, Journal of Philosophy of Education, 21(2).

Chuttur M.Y., 2009, Overview of the technology acceptance model: Origins, developments and future directions, Working Papers on Information Systems, 9(37).

Davis F.D., 1993, User acceptance of information technology: system characteristics, user perceptions and behavioral impacts, International Journal of Manmachine Studies, 38(3).

Davis F.D., Bagozzi R.P., Warshaw P.R., 1989, User acceptance of computer technology: a comparison of two theoretical models, Management science, 35(8).

Fawns T., 2019, Postdigital education in design and practice, Postdigital Science and Education, 1(1).

Fuentes Martinez A., 2021, Teachers' tactics when programming and mathematics converge (doctoral dissertation, University West).

Fuentes Martinez A., 2019, Gender and prior knowledge factors in pupils' beliefs about programming in mathematics, ICERI2019 Proceedings, 5703-5703.

Kamal S.A., Shafiq M., Kakria P, 2020, Investigating acceptance of telemedicine services through an extended technology acceptance model (TAM), Technology in Society, 60.

Kemp A., Palmer E., Strelan P., 2019, A taxonomy of factors affecting attitudes towards educational technologies for use with technology acceptance models, British Journal of Educational Technology, 50(5).

Kline S.J., 2003, What is technology [in:] R.C. Scharff, V. Dusek, Malden (eds), Philosophy of technology: The technological condition: an anthology, MA: Blackwell Publishers.

Larsson Å., 2017, 8 av 10 mattelärare osäkra på att lära ut programmering, Skolvärlden (sept 4).

Lee H.H., Fiore A.M., Kim J., 2006, The role of the technology acceptance model in explaining effects of image interactivity technology on consumer responses, International Journal of Retail \& Distribution Management, 34(8)

Leonardi P.M., 2007, Activating the informational capabilities of information technology for organizational change, Organization Science, 18(5).

Mattsson M., Eilertsen T.V. Rorrison D., 2011, What is practice in teacher education? [in:] eidem, A Practicum Turn in Teacher Education. Pedagogy, Education and Praxis, Rotterdam: SensePublishers.

Orlikowski W.J., 2000, Using technology and constituting structures: A practice lens for studying technology in organizations, Organization Science, 11(4). 
Orlikowski W.J., Iacono C.S., 2001, Desperately seeking the "IT" in IT research-a call to theorizing the IT artifact, Information Systems Research, 12(2).

Papert S., Harel I., 1991, Situating constructionism, Constructionism, 36(2).

Rule A.C., 2002, Mathematics in the real world: How people in different professions use mathematics, Open Educational Resources, 302.

Scherer R., Siddiq F., Tondeur J., 2020,. All the same or different? revisiting measures of teachers' technology acceptance, Computers \& Education, 143.

Shih B.Y., Shih C.H., Li C.C., Chen T.H., Chen Y.H., Chen C.Y., 2011, Elementary school student's acceptance of LEGO NXT: The technology acceptance model, a preliminary investigation, International Journal of the Physical Sciences, 6(22).

Teo T., Van Schalk P., 2009, Understanding technology acceptance in pre-service teachers: A structural-equation modeling approach, Asia-Pacific Education Researcher, 18(1).

Wenger E., 1998, Communities of practice: learning, meaning, and identity, Cambridge: Cambridge University Press.

\section{Summary}

In this article the author presents a critical analysis of the technology acceptance model when applied to teaching mathematics with computer programming. Programming is argued to escape the affordances of the model because of the implications carried by the conception of technology, both as materiality and as an alien element introduced in an existing environment. Instead, a practice acceptance model is outlined to cater for the peculiarities of programming in education, as a practice to be endorsed by the teaching community.

Keywords

technology acceptance model, practice acceptance model, teacher education, programming in mathematics 